\section{SUNKEN FIELDS IN THE DESERT OF PERU}

\section{Inge R. Schjellerup, Dr.h.c.dr.prof.hon.}

The National Museum of Denmark. Research and Exhibitions. Ethnographical Collection, Freddriksholms Kanal 12 DK 1220 Copenhagen K- Tlf.+45 33473218- Fax:4533473320 Inge.Schjellerup@natmus.dk

\section{Introduction}

$16^{\text {th }}$ century's South America was witness to the Spanish invasion and thus began the European colonization. At that time the Indians in the dry desert regions along the Pacific coast had developed many advanced agricultural systems of which one technique consisted of sunken fields, which are still in use in some locations.

The following paper deals with recent archaeological and anthropological investigations giving new insight in PreColumbian agricultural history and will hopefully add and inspire others to do research for comparative studies of similar types of sunken fields known from Micronesia [Cushing Falanruw 1994] Spain [Mørch 1989], and Algeria [Soldi 1982]. The end of my paper will address the case of Algeria very shortly. However literature on the subject is very spread and inadequate.

\section{Geographic and climatic conditions}

The Nazca plate that is moving downwards under the South American continental plate is shaping the dominating mounting range of the Andes at the Western side of South America. The back of this continental plate is only some $100 \mathrm{~km}$ from the Pacific Ocean which means that the low coastal region is wedged between the sea and the mountains raising to high altitudes. Along 3000 $\mathrm{km}$ a barren desert is stretched along the Pacific Coast of South America from Northern Peru into Northern Chile interrupted by fertile flood plains carrying water from the Andean mountain range. As rivers cross the desert and approach sea level, terrain adjacent to water courses and low-lying lands tends to have an increasingly higher water table, and these poorly drained soils are susceptible to salinization when irrigated.

Admittance to water for cultivation of crops was always a critical factor along the rainless coast caused by the cold
North running Humboldt Current which gives morning fog in the winter. The Humboldt stream has always been a very important factor for the very rich fish and bird lives on the coast and has been seen as a prime mover for the raise of civilization. People became permanently settled and, together with fishing, several crops were cultivated. Squash was cultivated from $8000 \mathrm{BC}$ and was used as recipients before the invention of pottery .

Only during the meteorological phenomenon known as El Niño that a temporary rise of the water temperature in the ocean, caused heavy rains along the coast and as it moved from the North towards the South the ecological balance in the sea was interrupted. This was because a limited amount of specific nutrition became more available than normal, and, as a result, maritime animal life is not only threatened but large numbers have actually died.

\section{Sunken Fields}

Irrigation from water canals from the West running rivers from the Andean mountain range was of great importance during normal conditions but other solutions to the scarcity of water are known from the discovery of sunken fields. Canal construction for irrigation started during the second millennium BC up valley.

Grand scale irrigation systems were developed by several of the Pre-Columbian cultures along the Western coast of Peru, but sunken fields dug into the level of the ground water were an alternative cultivation method in the past as well as the present. Sunken gardens supplemented canal irrigation by bringing slightly more land to cultivation.

Mahamaes, hoyas, jahüeyes, pukios or huachaques are some of the names for these field systems [Soldi 1982]. By analysing aerial photographs, several of these original field systems have been localised [Parsons 1975] but most of them have not been used for centuries.

Sunken fields are often placed along the foothills of the mountains where the ground water runs slowly but fast enough thereby avoiding immediate salinization effects. However, in these places fields are exposed to climatic alterations and/or sea level changes, which may bring 
intrusion of salt water into the ground water (Fig.1).

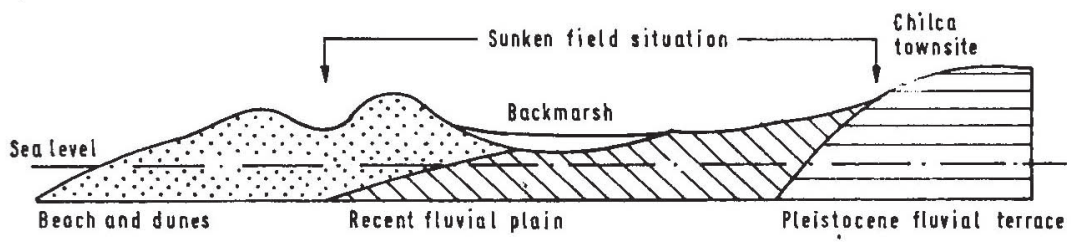

Fig.1 Sunken field situation from Smith 1979.

\section{Present and Past Locations}

When the first Spaniards arrived to Peru they were amazed to find a well-developed agriculture in the highlands but also in dry desert:

"It is an amazing thing to hear what they do in this valley. To provide the needed humidity, the Indians dig wide, deep holes in which they sow and plant the things I have described, and with the dew and dampness God makes them grow. But the seed of the corn in no wise sprout not yield if they did not put with each a head or two of the sardines they take in their nets. Thus, when they plant the corn, they lay them with the grain in the hole, and in this way it comes up and bears abundantly. Truly it is a remarkable thing never before seen that in a land where it never rains and the only water is light dew, people can live well. The water those of this valley drink comes from big, deep wells. In this vicinity of the sea they catch so many sardines that they supply these Indians with food and what they need for their plantings"...Cieza de León, 1557. [von Hagen transl. 337,338].

This early account from one of the most reliable Spanish chroniclers gives a very good description of the use of the sunken gardens near Chilca, South of Lima. Here sunken fields reach depths of 2-5 $\mathrm{m}$ and $20-100 \mathrm{~m}$ long and were still in use in the 1960s. The dug up soil were placed as dikes around the fields, which brought leeward for the winds. By placing the fields in this depth the ground water gave sufficient humidity to the cultivation of many earlier Indian crops as sweet potato, corn, beans, chilli peppers and cotton [Parsons, Psuty 1975:278]. Today, figs are cultivated in the sunken fields of Chilca with the use of irrigation.

As comparatively high level of ground water is needed (it is on a limited scale where you may and indeed could, possibly lay out mahamaes), therefore, many of the sunken fields in Chilca became destroyed with increased salinization levels as time went on.

\section{Past and present sunken fields}

In 2007 archaeological/anthropological research was conducted near the provincial town of Trujillo where several pre-Columbian, as well as modern, sunken fields are found (Fig.2).

Several localities in Northern Peru, North of Trujillo city, have been utilized the same ways employed at Chan Chan. [Mosely 1969]

Chan Chan was the capital of the Chimú Empire [ca. 800 - 1470]. The Chimu culture is known for its largescale irrigation systems, but it also developed sunken fields. Chan Chan is now the biggest mud brick city in the world, covering an area of some $6 \mathrm{~km} 2$. It has nine palaces made of adobe, sun dried mud bricks and they were built successively. When a ruler died, his palace was closed and the new ruler had to build his own palace. Chan Chan has several palace-enclosures with sunken fields inside and outside.

Much of the building material probably came from the excavations of sunken fields. Such fields extended inland at lEast $4 \mathrm{~km}$.

After flooding by El Niño events, the canal irrigation systems were disrupted and the sunken fields increased in numbers and in size. Authors believe that many of the sunken fields in Peru developed because of population 


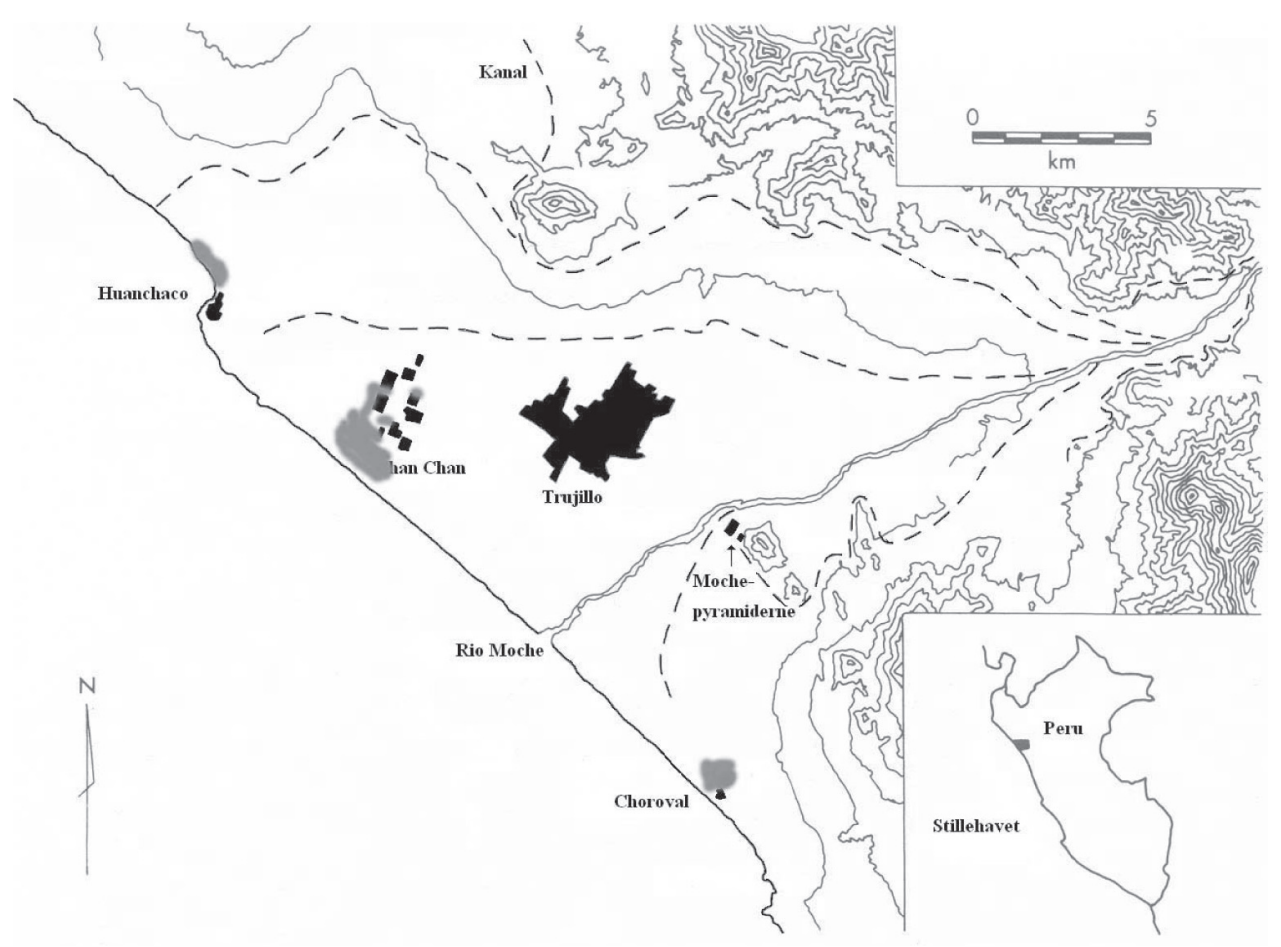

Fig. 2 Map of sunken field locations on the Northern coast of Peru.

growth under the Chimu dynasty around 1100 AD. As irrigated cultivation may have produced only one crop per year, the addition of sunken fields in use all the year round would have made a significant contribution to food supplies. Early remaining sunken field, located $4 \mathrm{~km}$ inland in the Moche Valley, are today 10$12 \mathrm{~m}$ above the ground water level, and are not functional.

In Chan Chan, investigations were carried out in one of the late palaces called Bandalier, where three sunken fields are situated (Fig.3).

The three sunken fields were measured and investigated. The largest measured $52 \mathrm{~m}$ long and $12 \mathrm{~m}$ wide, the next $26 \mathrm{~m}$ by $19 \mathrm{~m}$ and the smallest divided into two sections $17 \mathrm{~m}$ by $16 \mathrm{~m}$. The sand from the excavations were large earthworks/banks placed on one side from the largest sunken field and had been moved away from the other two sunken fields.

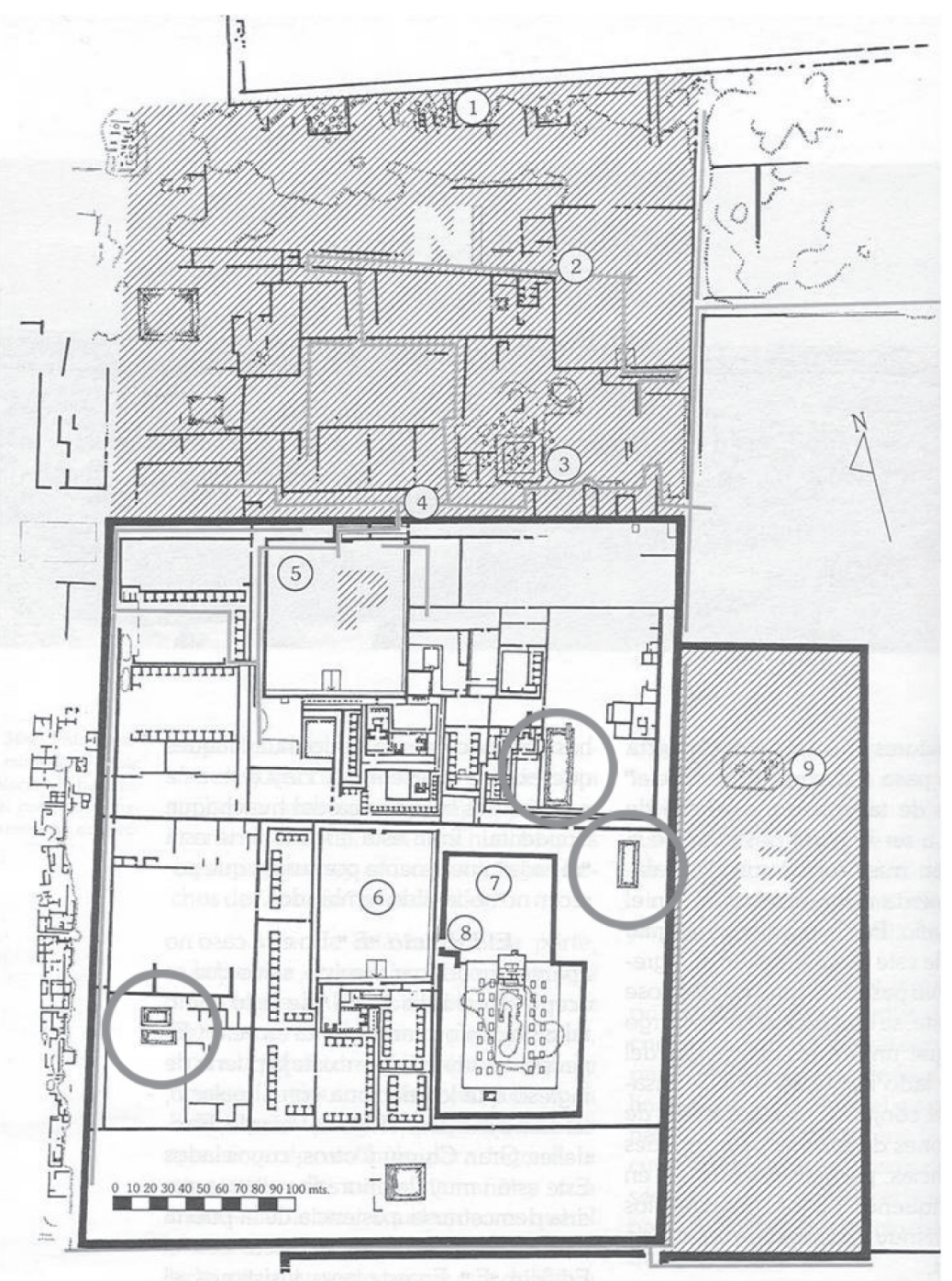

Fig.3 The Palace of Bandelier, Chan Chan, courtesy of C. Campana. 


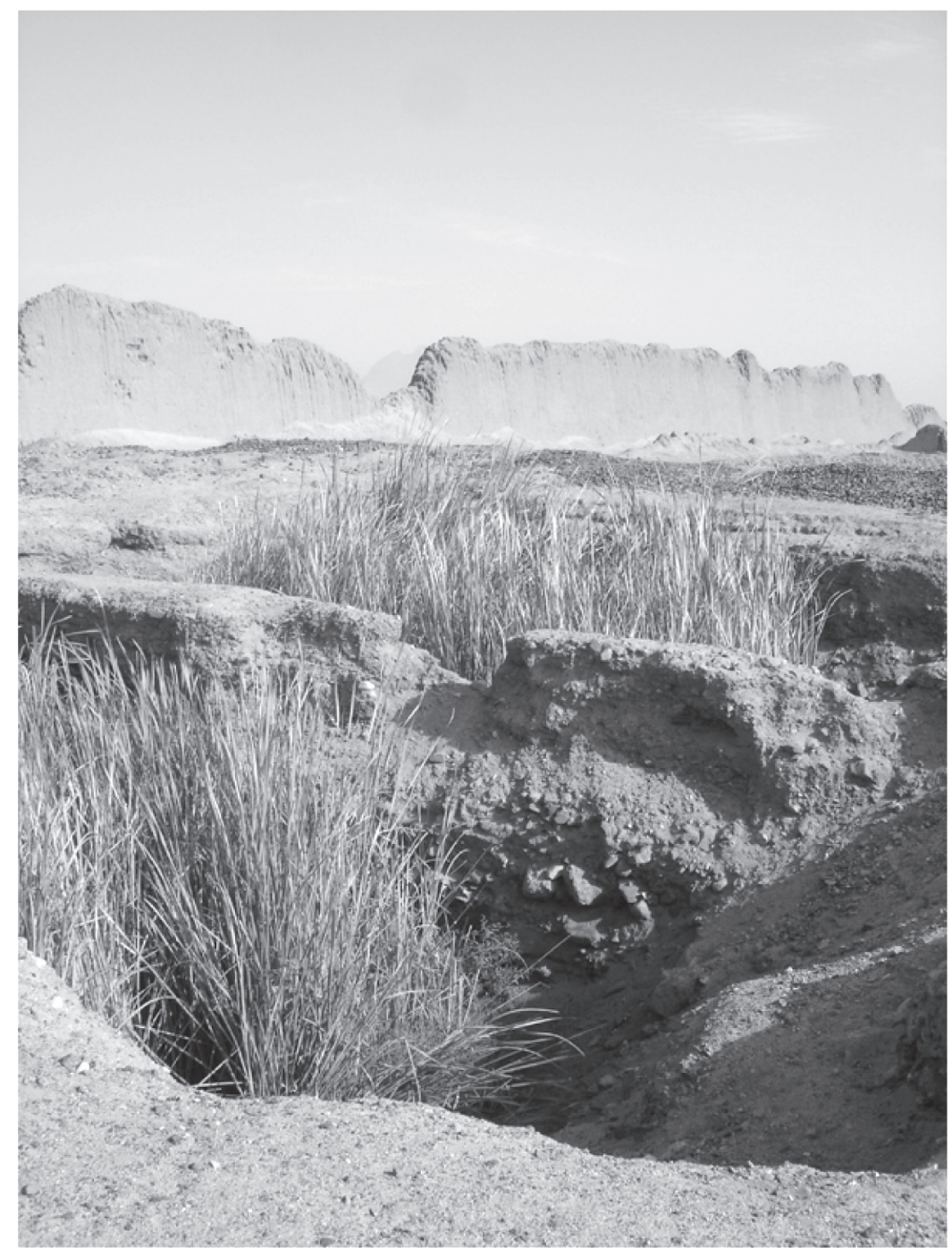

Fig.4 The double sunken field in Bandelier with remains of cobblestones as walls.Foto IS.

A cobble masonry wall that prevents slide failures of sandy soil protected the up-to- $10 \mathrm{~m}$-deep side slopes. All the sunken fields had remains of only one stone layer along their sides (Fig.4).

Common for all the sunken fields in Chan Chan today, is that they all grow totora reed [Scirpus californicus].

The original excavations for the sunken fields were rather deep. The depth to the present water level was about 2 meters, and from the water level to the bottom 2, 75meters in the largest field, $2 \mathrm{~m}$ in the middle and $1,10 \mathrm{~m}$ and $1,95 \mathrm{~m}$ in the smallest. $\mathrm{PH}$ was measured to be 7. Centuries ago salinization became a problem in the South-Eastern part of Chan Chan and from the 18th century ancient documents describe Chan Chan as the salt mines settlement of Chan Chan.[Campana 2006:295]
At Choroval $20 \mathrm{~km}$ South of Trujillo, a large area near the seashore, several ancient sunken fields are in use not only for totora reed, but also for the growing of tomatoes, broccoli, calabashes and other products.

Many of the fields lie in deep sand dunes. All the sunken fields were drawn to scale and cover an area of 16.133 ha (Fig.5). Here, excavations were carried out in three sunken fields to get more information on the construction technique. Two trenches in two sunken fields showed only one level of use and no stone layers.

Interesting was the trace of the earlier excavation in the cross section of the excavation. 


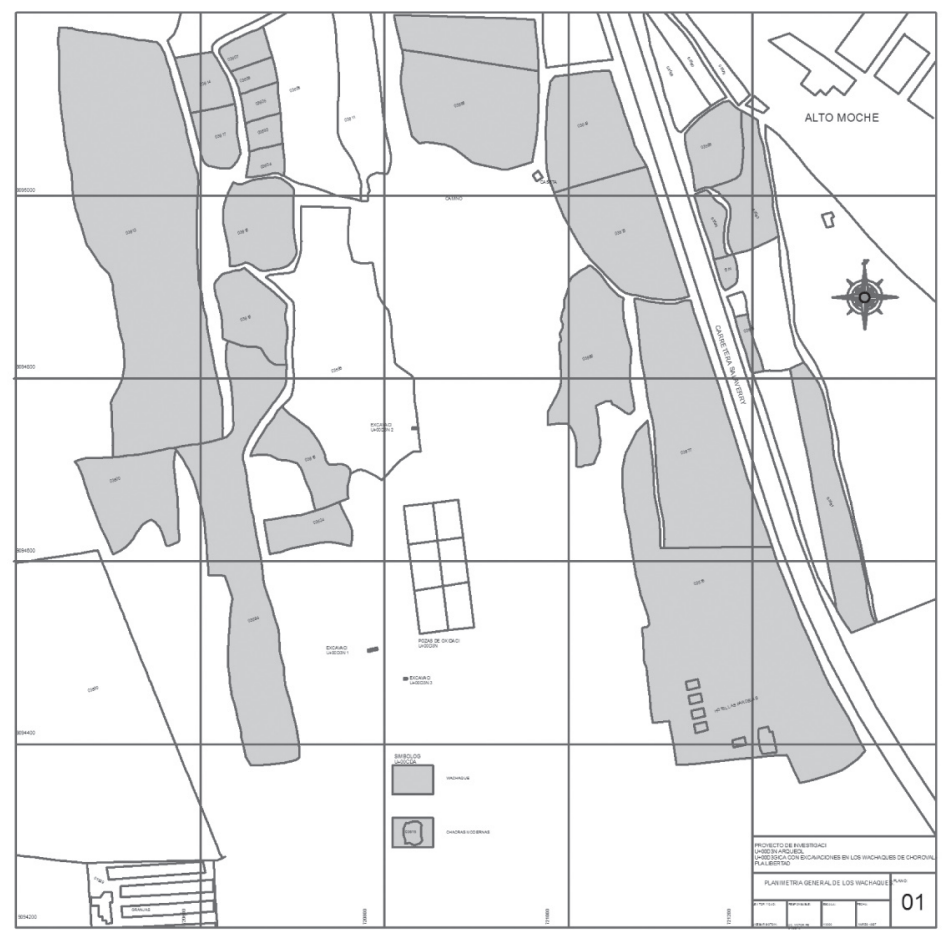

Fig.5 The sunken fields in Choroval, $20 \mathrm{~km}$ South of Trujillo.

A trench $10 \times 2,5 \mathrm{~m}$ in the corner of one of the sunken fields showed no stones at the sides but the stratigraphy gave evidence of two sequences of use with two dark grey layers showing the original surface of the field (Figs.6,7). As both the earth and sand here are relatively intact, this may be the reason behind the absence of stonewalls.

Potsherds, a typical design with raised dots from the Chimu period gave evidence of the age of the sunken fields (around year 1000).

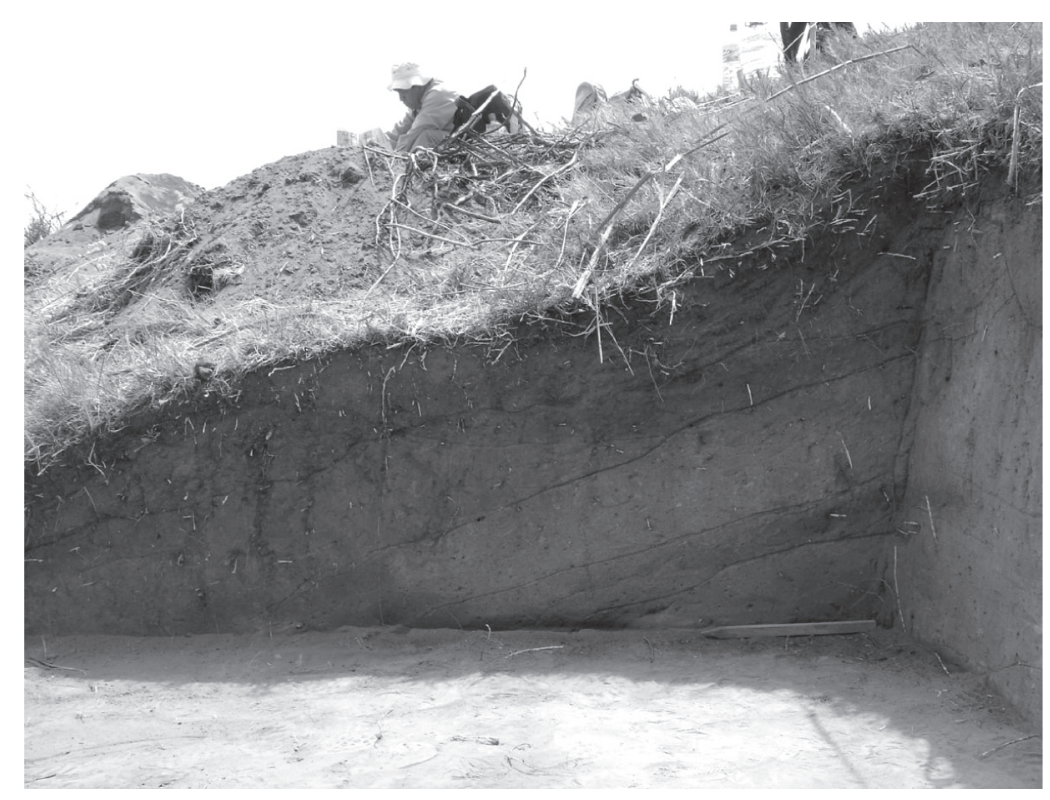

Fig.6 Excavation in a sunken field in Choroval.Foto IS 


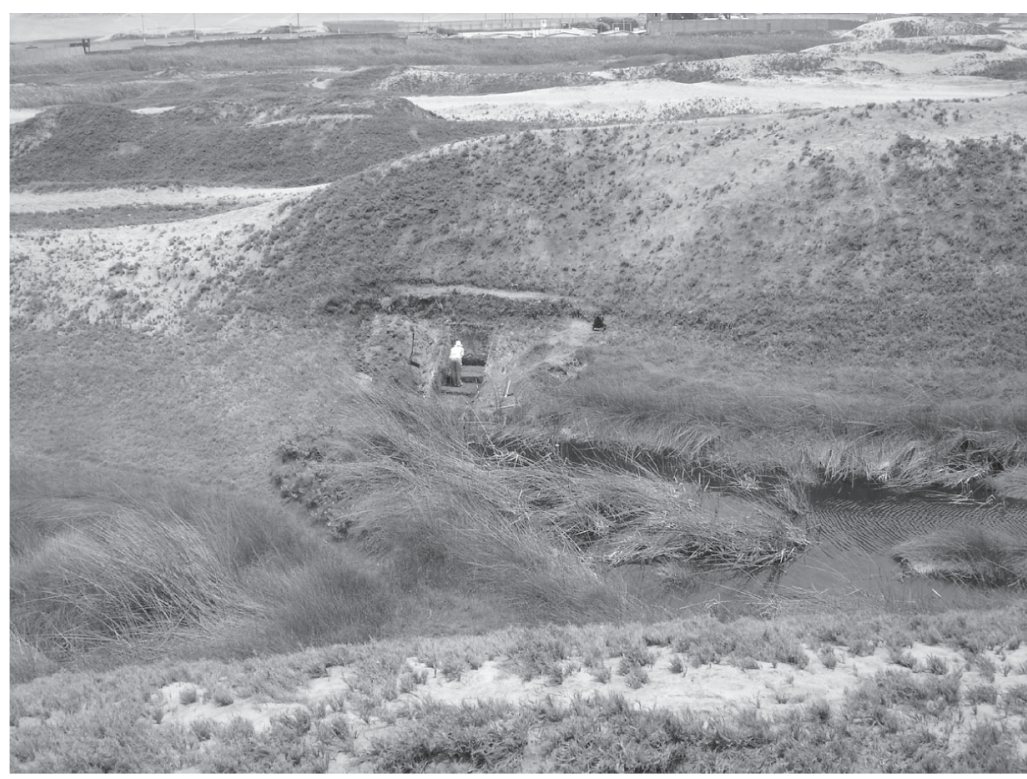

Fig. 7The dark layers show the levels of use of the sunken field in Choroval.Foto IS

Despite their coastal location, these gardens did not suffer from saltwater intrusion, because their engineers knew, that constant upslope irrigation, does suppress the layer of brackish water at the coast. Remains of several cockleshells and some fish bone had been part of the dairy. Pollen samples were analysed but the pollen were in such bad condition that they were of no use. But plant data from earlier research indicate that food plants, especially maiz and squash, were the main crops produced in the sunken gardens in Choroval [Pozorski 1982:193].

\section{Two possible planting methods}

Smith has suggested that it would have been advantageous to furrow the soil surface so the sowing could take place in a low salinity environment as salt tends to build-up in the ridges or any areas of the field left at relatively higher and drier level. Another advantage would be that water could be led in from a surface canal, as and when required (Fig.8).Surface irrigation water in the context of sunken gardens culture probably took place in some cases. Its use would have been most effective for:

1.flushing out accumulated salts;

2.2. supplementing the existing supply of nutrients,

3.3. adding fine sediment to improve the consistency of soil [Smith 1979:393].

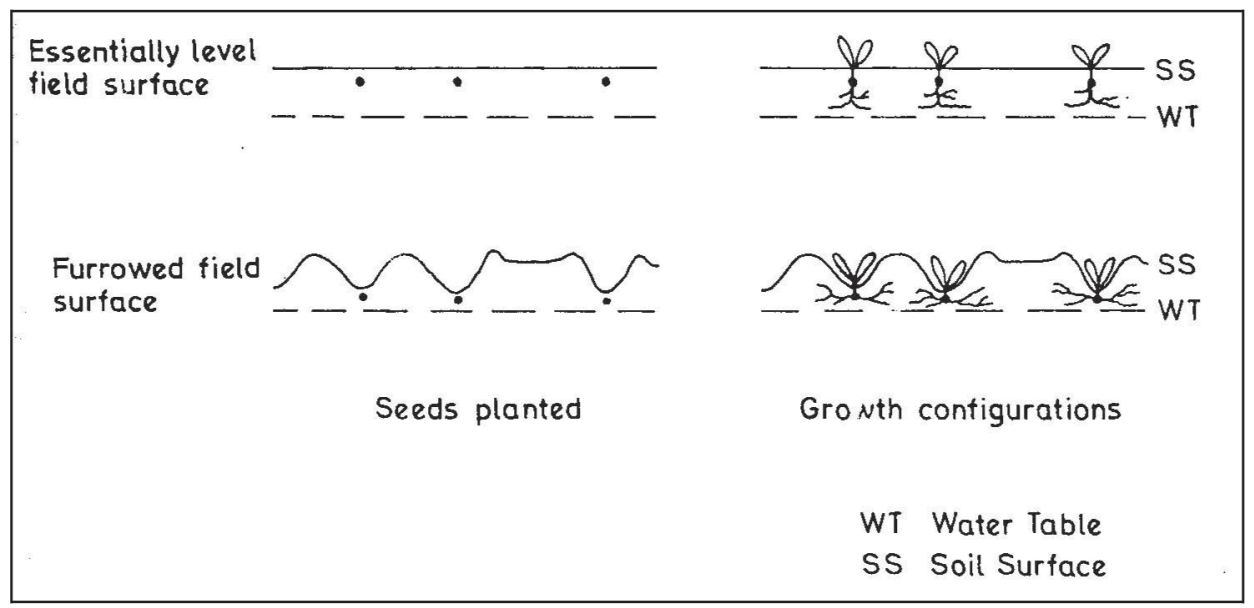

Fig.8 Two planting methods from Smith 1979. 


\section{Modern use}

A few kilometres North of Chan Chan in the fishing village of Huanchaco, more than three hundred sunken fields are still in use. They are all situated at the Pacific Ocean. In the 1930s, some fishermen decided to make new sunken fields as they needed more totora to construct their fishing reed boats the so called cabalittos, little horses (Fig.9) Previously, they collected their entire reed in Chan Chan, getting the mules to carry the heavy loads.

They started with only few sunken fields, but with the help of an ONG, more sunken fields are still being constructed. inland and then taken back to the private owners, where the reed is kept in storage. During wintertime it takes $11 / 2$ months to dry and in summertime it takes only 2 weeks. Fishermen use about one reed boat per month before they have to construct a new one. Fishing is still carried out from these reed boats in a distance reaching to several kilometres from the seashore at the Pacific coast.

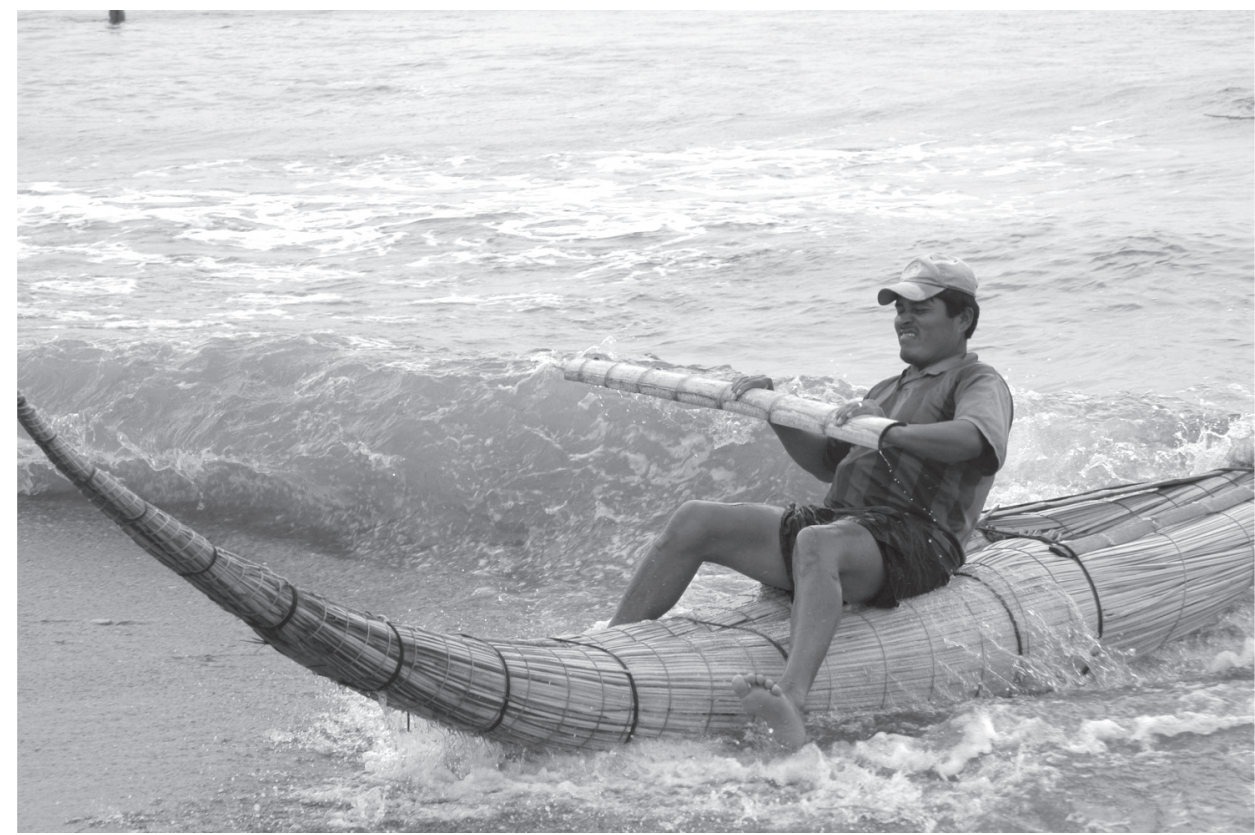

Fig.9 Reed boat for fishing, Huanchaco. Foto IS.

The measurements of some fields show various stages of use; some totally harvested while others only partly, depending on the need. The reeds are also used as hedges giving shelter from the wind. Every family owns from 5- 8 fields. Sizes vary from 3-4 m wide to $10 \mathrm{~m}$ long. The reed grows to 5-6 m high and may get quite thick. The same plant reproduces for up to ten years. If there is too much peat, the fisherman will dig it up leaving more space for the new totora reed.

Once a year a field gets harvested but only in a staggered manner (Fig.10). The totora reeds are dried a little further,
It was the same principle, which Thor Heyerdahl used in the construction of his reed boats. Most of the reed are used for the boat construction, but some is also used for building hedges and for other variable functions in the tourist industry. 


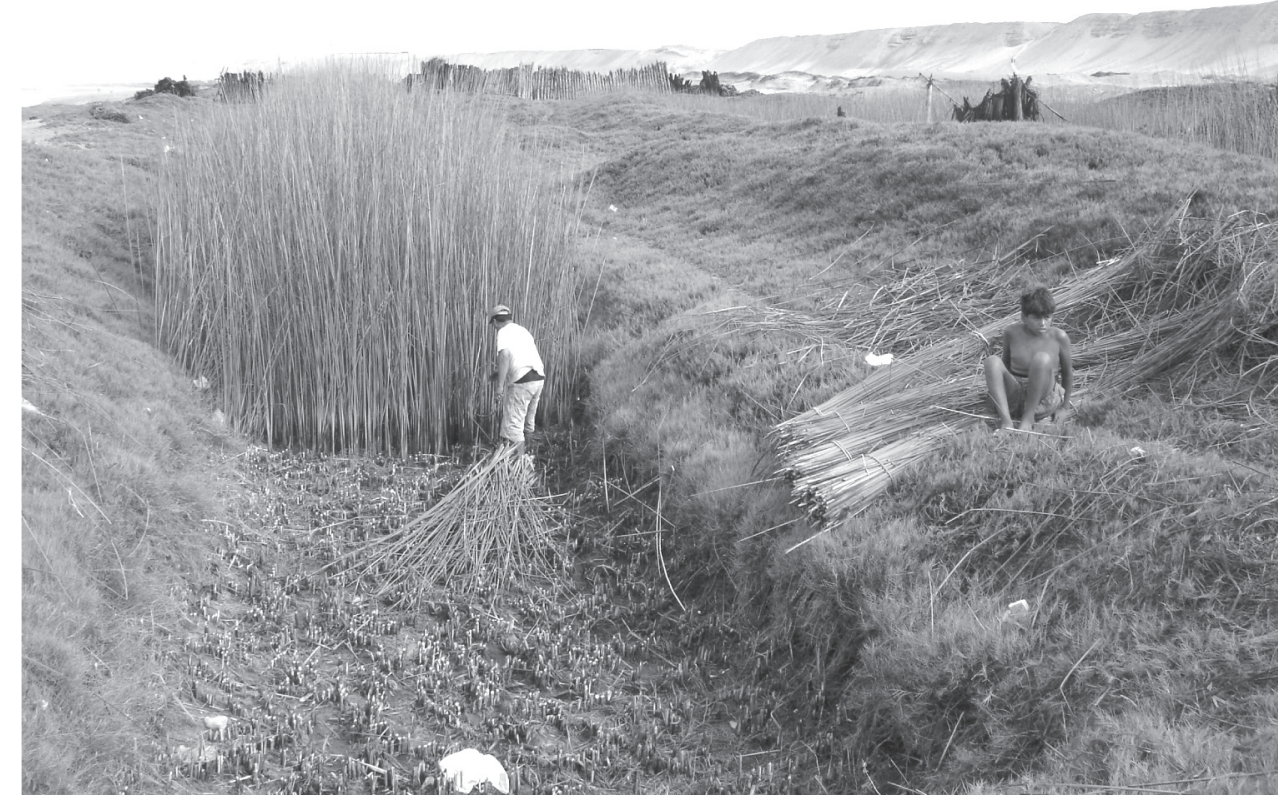

Fig.10 Harvest of totora reed in a sunken field in Huancaco.Foto IS.

Most literature on the subject focuses only on the use of totora as material for making reed boats. This, however, is a very limited way of thinking. Totora reed is a multipurpose plant. It is used for making mats to sleep, and sit, on and the mats are also used in house construction. It is very nutritious with a high content of iodole as it can be consumed. It is also used medicinally as an astringent, to lower fever, and as food for cattle [Brack 1999].

Two generations ago the Huanchaco population had other sunken fields further inland for the cultivation of crops. Working the fields was carried out when the sea was too rough to go fishing. But life has changed, as fishermen prefer to work as day labourers in construction or in tourist-related work and buy their food for cash. However, man's combination of both rural and maritime work are still being practiced in some places along the coast of Peru
Finally I would very briefly mention the Algerian case of "Ghitane" in the Souf region for comparative reasons. Here man made hollows of 6 to 12 meters in depth surrounding them with palisades to protect them from the $\mathrm{d}$ riving sand. Palm trees are here planted in the waterbearing layer. They have been called pancake oases. In other cases, sand terraces prevent palm trees from being engulfed by blowing sand. [Nace 1970] Mentioned that they are disappearing because of higher water levels.

Though the techniques of sunken fields have been used in several places, and maybe used in other dry environments, it is surprising how minute the amount of literature that exists on the topic. I hope that my paper will contribute to inspire new research on this subject in other regions. 


\section{References}

1.Brack Egg, Antonio, Diccionario Enciclopedico de plantas utiles del Peru. PNUD,1999, p.549.

2.Campana, Cristóbal, Chan Chan del Chimo.Editorial Orus, Peru, 2006.

3.Cushing Falanow, Margie V, Food Production and Ecosystem Management on Yap. ISLA: A Journal of Micronesien Studies, 2,1:5-22. University of Guam, 1994.

4.Moseley, Edward M, Assessing the Archaeological Significance of Mahamaes. American Antiquity, Vol. 34, No.4:485-487, 1969.

5.Mosely, Michael E. and Kent C.Day, Chan Chan Andean Desert City. University of New Mexico Press. 1982.

6.Nace, Raymond, Man's perpetual quest for water. Unesco Courier 1970:4-11.

7.Parsons, Jeffrey R., The Archaeological Significance of Mahamaes Cultivation on the Coast of Peru. American Antiquity. Vol.33,no.1:80-85, 1968.

8.Parsons, Jeffrey R. et N.P. Psut, Sunken Fields and Prehispanic Subsistence on the Peruvian Coast. American Antiquity. Vol.40.No.3:259-282, 1975.

9.Pozorski, Theresa G.

10.Subsistence Systems in the Chimú State. in Moseley and Day: Chan Chan, Andean Desert City. Ed. M. Moseley and K. Day. University of New M79.exico Press, 177-196, 1987.

11.Smith, Richard T., The development and Role of Sunken Field Agriculture on the Peruvian Coast. The Geographical Journal, vol. 145:387-400, 1979.
Pontificia Universidad Católica del Peru, 1982

13.Topic, John R. and Theresa L. Topic,The rise and decline of Cerro Amaru: an Andean shrine during the early intermediate period and middle horizon in Ancient images, ancient thought: the archaeology of ideology, Ed: A. Sean Goldsmith et al, Univ. of Calgary archaeological association, Calgary, Cananda, p 167-180, 1992.

14.Topic, Theresa L y John R. Topic, Arquitectura en Chan Chan en Chan Chan: Chimú Metropoli, ed: Rogger Ravines, Institute de Estudios Peruanos, Lima, Perú, 1980 . 